\title{
METHOD DEVELOPMENT AND VALIDATION OF THE CHROMATOGRAPHIC ANALYSIS OF FLUTICASONE PROPIONATE AND SALMETEROL XINAFOATE COMBINATION IN SOLUTIONS AND HUMAN PLASMA USING HPLC WITH UV DETECTION
}

\author{
MOHAMMAD JAMAL A. SHAMMOUT ${ }^{1 *}$, HAMMAM B. YOUSEF ${ }^{2}$, KHALID H. ABU-SHANDI ${ }^{2}$, MOHAMMAD I. \\ ALOMARI ${ }^{3}$, MOHAMMAD R. HASAN ${ }^{4}$, ATEF O. AL-OTHMAN ${ }^{5}$, WALEED A. MANASREH ${ }^{6}$
}

1Department of Basic and Applied Sciences, Zarqa University College, Al-Balqa Applied University, Al-Salt 19117, Jordan, ${ }^{2}$ Department of Chemistry and Chemical Technology, Faculty of Science, Tafila Technical University, Tafila, Jordan, ${ }^{3}$ Department of Chemistry, Faculty of Arts and Sciences, University of Petra, Amman, Jordan, ${ }^{4}$ Bioanalytical Lab, Jordan Center for Pharmaceutical Research (JPCR), Amman, Jordan, ${ }^{5}$ Faculty of Applied Medical Sciences, Al-Ahliyya Amman University, Amman, Jordan, ${ }^{6}$ Department of Chemistry, Faculty of Science, Mutah University, Karak, Jordan

*Email: dr.mj-shammout@bau.edu.jo

Received: 03 Apr 2021, Revised and Accepted: 29 May 2021

\section{ABSTRACT}

Objective: A simple, Rapid, and sensitive HPLC method utilizing UV detection was developed and validated for the simultaneous estimation of Fluticasone propionate (FP) and Salmeterol xinafoate (SX) in solutions and in vitro human plasma.

Methods: Chromatographic analysis was done on SUPELCO ${ }^{\circledR}$ RP-C18 column $(150 \times 4.6 \mathrm{~mm}, 5 \mu \mathrm{m}$ particle size) with an isocratic mobile phase composed of methanol, acetonitrile, and water (50:20:30, v/v) mixture while flow rate was set to $1 \mathrm{ml} / \mathrm{min}$. Detection with UV at maximum absorbance wavelength $\left(\kappa_{\max }\right)$ values of 236 and 252 for FP and SX, respectively. Spiked plasma samples were liquid-liquid extracted by diethyl ether and reconstituted using methanol.

Results: Method was accurate and precise over a linear $\left(\mathrm{R}^{2}>0.995\right)$ range of $(0.067-100 \mu \mathrm{g} / \mathrm{ml})$ and $(0.0333-50 \mu \mathrm{g} / \mathrm{ml})$ for FP and SX, respectively. $\mathrm{LOD} / \mathrm{lOQ}$ values were $0.13 / 0.6$ and $0.06 / 0.3 \mu \mathrm{g} / \mathrm{ml}$ for FP and SX, respectively.

The developed method was successfully applied for the analysis of FP and SX in spiked human plasma samples. The method is considered to be accurate and precise over a linear $\left(\mathrm{R}^{2}>0.9969\right)$ range of $(6.67-66.67 \mu \mathrm{g} / \mathrm{ml})$ and $(3.33-33.3 \mu \mathrm{g} / \mathrm{ml})$ for FP and SX, respectively. Extraction efficiency was approved by recovery values of (94.98-102.46 \%) and (96.54-102.62 \%) for FP and SX, respectively.

Conclusion: This validated method revealed simple and cheap extraction procedures and detectors, non-buffered mobile phase, and short retention times with excellent resolution.

Keywords: Fluticasone propionate, Salmeterol xinafoate, HPLC UV, Method validation, Human plasma

(C) 2021 The Authors. Published by Innovare Academic Sciences Pvt Ltd. This is an open access article under the CC BY license (https://creativecommons.org/licenses/by/4.0/) DOI: https://dx.doi.org/10.22159/ijap.2021v13i4.41678. Journal homepage: https://innovareacademics.in/journals/index.php/ijap

\section{INTRODUCTION}

Glucocorticosteroids and corticosteroids are classes of steroid hormones naturally synthesized in the adrenal cortex from cholesterol; regulate many aspects of metabolism and immune functions [1]. Fluticasone propionate (FP) (fig. 1a), a new generation of glucocorticosteroids, is considered as one of the important medications for asthma diseases. It has a strong therapeutic effect against bronchi inflammation. Salmeterol Xinafoate (SX) (fig. 1b) is a new long-acting $\beta 2$-agonist used in the treatment of nocturnal airway obstruction and has proved to be highly effective in this aspect as well $[2,3]$.

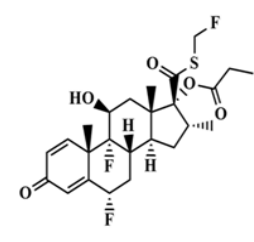

(a)

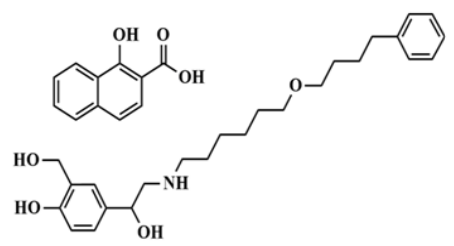

(b)
Fig. 1: Chemical structure of fluticasone propionate (a) and salmeterol Xinafoate (b)

The two drugs are formulated as dry powder inhalers or pressurized metered-dose inhalers individually or in the combined formulation.
However, it is not yet known whether using Salmeterol xinafoate (SX) alone or in combination with Fluticasone propionate (FP) constitutes the best treatment $[4,5]$.

Several chromatographic techniques have been published in the literature for analysis purposes of fluticasone propionate (FP) and/or, salmeterol xinafoate (SX) in their pharmaceutical preparations and different matrices. For example these methods include UVspectrometric methods [6, 7], HPLC with UV detection methods [8-13], HPLC-MS/MS methods [14, 15], UPLC-MS/MS methods [16, 17], UPLCPDA method [18], and HPTLC method [19, 20].

In this article, a new validated method has been developed for the simultaneous estimation of fluticasone propionate (FP) and salmeterol xinafoate (SX), combined in spiked human plasma samples using High-Performance Liquid Chromatography (HPLC) with UV detection. The method includes a simple solvent extraction technique for recovering fluticasone propionate (FP) and salmeterol xinafoate (SX) from spiked human plasma samples. According to the literature survey, No HPLC method with UV detection for simultaneous assay of fluticasone propionate (FP) and salmeterol xinafoate (SX) in the human plasma was reported.

\section{MATERIALS AND METHODS}

\section{Reagents}

The studied drugs, Fluticasone Propionate (FP), Salmeterol Xinafoate (SX), and $\beta$-Estradiol ( $\beta E$ ) were supplied by SIGMA and used without any further treatment. Highly pure Methanol, Acetonitrile (HPLC grade) were bought from TEDIA. Deionized 
water was prepared by running distilled water through an electrically charged resin. Distilled water was prepared using the ELGA distillator type RESERVOIR.

\section{Instrumentation}

A UV-1800 UV-Vis spectrophotometer was used to scan the UV-Vis spectrum and to locate $\lambda_{\text {max }}$ during the study. I-Series LC-2030 High Performance Liquid Chromatography (HPLC) from SHIMADZU with UV/Visible detector was used to develop the chromatographic method. Two types of columns, SUPLECO (C18, $50 \times 4.6 \mathrm{~mm}, 5 \mu \mathrm{m}$ ) column and HYPERSIL (RP C18, $250 \times 4.6 \mathrm{~mm}, 5 \mu \mathrm{m}$ ) column were tested to optimize the best separation of FP and SX drugs simultaneously. SUPELCO (RP C18 $250 \times 4.6 \mathrm{~mm}, 5 \mu \mathrm{m}$ ) column was suitable for FP and SX drugs for both solutions and plasma samples. During the study, the column temperature was fixed at $25^{\circ} \mathrm{C}$. Autosampler type is I-Series LC-2030 from SHIMADZU. Many trials have been performed to optimize the mobile phase in this study. Utilizing the physio-chemical data about FP and SX [21], the mixture of methanol, acetonitrile, water (50:20:30, v/v) eluted on isocratic mode at a flow rate of $1 \mathrm{ml} / \mathrm{min}$ is suitable for analysis in this study. The applied injection volume was $20 \mu \mathrm{l}$.

\section{Preparation of solutions}

400 and $200 \mu \mathrm{g} / \mathrm{ml}$ methanolic stock solutions of FP propionate and SX were prepared by separately dissolving 20 and $10 \mathrm{mg}$ of each drug respectively in $50 \mathrm{ml}$ volumetric flasks. Five methanolic standard solutions were prepared to construct the calibration curves having the following concentrations: $50,10,1,0.1$, and 0.05 $\mu \mathrm{g} / \mathrm{ml}$. Nine methanolic combined standard solutions of FP and SX mixture were prepared to have the following concentrations: $[\mathrm{FP}]=300,200,120,40,20,8,4,0.4$ and $0.2 \mu \mathrm{g} / \mathrm{ml}$ and $[\mathrm{SX}]=150$, $100,60,20,10,4,2,0.2$ and $0.1 \mu \mathrm{g} / \mathrm{ml}$. A $50 \mu \mathrm{g} / \mathrm{ml}$ methanolic solution of the internal standard $\beta$-Estradiol $(\beta E)$ was prepared by dissolving $5 \mathrm{mg}$ of $\beta$-Estradiol $(\beta E)$ in a $100 \mathrm{ml}$ volumetric flask [22]

Four separate methanolic quality control solutions (QCs) each of which, FP and SX mixtures were prepared using the stock solution to separate eight $10 \mathrm{ml}$ volumetric flasks to obtain the following concentrations: $(240,160,2$ and $0.6 \mu \mathrm{g} / \mathrm{ml})$ and $(120,80,1$ and 0.3 $\mu \mathrm{g} / \mathrm{ml}$ ) for FP and SX, respectively. The above solution of $\beta \mathrm{E}$ was used as an internal standard.

\section{Methods validation}

The developed HPLC methods with UV detections for the analysis of FP and SX in plasma were validated according to the common validation guidelines such as Food and Drug Administration (FDA) [23] and International Conference on Harmonization(ICH) [24, 25]. The results were evaluated according to the acceptance criteria of the selected guidelines.

To validate the methods, seven calibration curves were constructed for the linearity test. Each calibration curve consists of 9 points. For each point, a volume of $0.5 \mathrm{ml}$ of each of $\mathrm{FP}, \mathrm{SX}$, and $\beta \mathrm{E}$ as internal standard was withdrawn and mixed into a separate vial. The seven calibration curves were injected directly into the HPLC. The limit of detection (LOD) and limit of quantification (LOQ) were determined from the calibration curves based on visual evaluation, the standard deviation of the response, and the slope. The detection limit was based on a visual evaluation by injecting a set of low concentration samples. At the same time, the concentration is gradually reduced until obtaining the lowest concentration without getting precise and accurate replications of this concentration. The detection limits were determined for FP and SX starting from $5 \mu \mathrm{g} / \mathrm{ml}$, then gradually reducing the concentration to 0.05 and $0.01 \mu \mathrm{g} / \mathrm{ml}$ for FP and SX, respectively.

\section{System/Method accuracy and precision}

Four QC solutions with the following concentration $(80,53.33,0.67$ and $0.2 \mu \mathrm{g} / \mathrm{ml})$ and $(40,26.67,0.33$ and $0.1 \mu \mathrm{g} / \mathrm{ml})$ for FP and SX, respectively were prepared as mixture for system precision test. For each quality control sample, a volume of $0.5 \mathrm{ml}$ of each of FP, SX, and $\beta \mathrm{E}$ as internal standard was withdrawn and mixed into a separate vial and injected (for method precision), and one replicate series were injected six times for each concentration (for system precision) into the HPLC. For the accuracy test, the above six replicates of the four QCs were injected with parallel to complete calibration standards with suitable concentration points.

\section{Long-term stability test at room temperature and zero ${ }^{\circ} \mathrm{C}$}

This test was divided into five cycles, each of which is a 3-day time interval. Three QC solutions with the following concentrations (80, 53.33, and $0.67 \mu \mathrm{g} / \mathrm{ml})$ and $(40,26.67$, and $0.33 \mu \mathrm{g} / \mathrm{ml})$ for FP and SX respectively were prepared in triplicate for every cycle. The QC samples were stored at room temperature and $0{ }^{\circ} \mathrm{C}$ and then were injected in parallel to the QCs for every cycle. In each cycle, the QCs and the calibration curve standards were injected once in the HPLC.

\section{Acidic, basic, and oxidative conditions stability test}

The stability of FP and SX methanolic solutions in acidic/basic/oxidative conditions was tested by taking $5 \mathrm{ml}$ of $1 \mathrm{M}$ $\mathrm{HCl}$ (for acidic condition stability test) or $1 \mathrm{M} \mathrm{NaOH}$ (for basic condition stability test) or $\left(30 \% \mathrm{H}_{2} \mathrm{O}_{2}\right.$ oxidative condition stability test) in $10 \mathrm{ml}$ volumetric flask then spiked the analyte into the $\mathrm{HCl}$, $\mathrm{NaOH}$ or $30 \% \mathrm{H}_{2} \mathrm{O}_{2}$ solutions to get the exact QC solution concentration. The QC samples were kept in the $37^{\circ} \mathrm{C}$ water bath for $3 \mathrm{~h}$. Then, the $\mathrm{QC}$ samples were neutralized with $5 \mathrm{M} \mathrm{NaOH}$ (for acidic condition stability test)/HCl for basic condition stability test) to $\mathrm{pH}$ 7. The flasks were filled with methanol to obtain the following concentrations $(80,53.33,0.67$, and $0.2 \mu \mathrm{g} / \mathrm{ml})$ and $(40,26.67,0.33$, and $0.1 \mu \mathrm{g} / \mathrm{ml}$ ) of FP and SX, respectively, for acidic, basic, or oxidative conditions stability test. For each quality control sample, a volume of $0.5 \mathrm{ml}$ of each of $\mathrm{FP}, \mathrm{SX}$, and $\beta \mathrm{E}$ as internal standard was withdrawn and mixed into a separate vial and injected in the HPLC with calibration curve's standards.

\section{Analytical method development and optimization for FP and SX combination in solutions using HPLC with UV detector}

Methanolic stock solutions of $\mathrm{FP}, \mathrm{SX}$, and $\beta \mathrm{E}$ at $0.1 \mathrm{mg} / \mathrm{ml}$ were prepared by dissolving $10 \mathrm{mg}$ of each drug in three different $100 \mathrm{ml}$ volumetric flasks. Working solutions of $10 \mu \mathrm{g} / \mathrm{ml}$ of each solution were prepared by dilution of $1 \mathrm{ml}$ of stock solutions in $10 \mathrm{ml}$ methanol. The obtained solutions were scanned in the UV-Vis spectrophotometer from 200-800 $\mathrm{nm}$ to monitor the wavelengths with maximum absorbance $\left(\lambda_{\max }\right)$ for each drug. For HPLC analysis, $100 \mu \mathrm{g} / \mathrm{ml}$ solutions of FP, SX, and $\beta \mathrm{E}$ were prepared by dissolving $5 \mathrm{mg}$ of each drug in methanol in three different $50 \mathrm{ml}$ volumetric flasks.

Method development and optimization for the simultaneous
analysis of FP and SX in human plasma using HPLC with UV detector

\section{Extraction method for spiked human plasma samples}

Two milliliters of blank plasma were inserted into a $10 \mathrm{ml}$ test tube and a volume of $150 \mu \mathrm{l}$ of methanol was added and mixed by a vortex for one minute. The resulting mixture was mixed with $2 \mathrm{ml}$ of diethyl ether by a vortex for one minute. The mixture was centrifuged at $4000 \mathrm{rpm}$ for $15 \mathrm{~min}$. Two layers were obtained. Aliquot of $2 \mathrm{ml}$ of the upper layer (diethyl layer) was withdrawn and transferred to a new test tube and dried by using the flow of nitrogen gas. A volume of $3 \mathrm{ml}$ of methanol (HPLC grade) was added to the dried test tube and mixed by a vortex for one minute. The resulting solution was transferred into a vial and injected into the HPLC. Unsatisfactory results were obtained when acetonitrile was used as a solvent instead of methanol.

To construct a calibration curve, five methanolic standard solutions of fluticasone propionate and Salmeterol Xinafoate mixture were prepared by dilution from $2000 \mu \mathrm{g} / \mathrm{ml}$ stock solutions of FP and SX. Different volumes were withdrawn from each stock solution and spiked into $2 \mathrm{ml}$ of pure plasma in $10 \mathrm{ml}$ test tubes using the same extraction procedure described above for blank solution to obtain the following concentrations $(100,70,50,30$, and $10 \mu \mathrm{g} / \mathrm{ml})$ for each medication. The same method was used to prepare methanolic QC solutions for each medication of the four separated solutions. The obtain the following final concentrations $(20,40,60$, and $80 \mu \mathrm{g} / \mathrm{ml})$ of both FP and SX. 


\section{RESULTS AND DISCUSSION}

\section{Method optimization}

$\lambda$-max values were determined to be (236, 252, and $202 \mathrm{~nm}$ ) for FP, SX, and $\beta E$, respectively. $\lambda_{\max }$ values are very similar to those found in the literature for FP and SX $[26,29,32]$. The retention times were $(10.6,1.8$, and $6 \mathrm{~min}$ ) for $\mathrm{FP}, \mathrm{SX}$, and $\beta \mathrm{E}$ respectively as shown in (fig. 2). The constructed calibration curves shown in (fig. 3) have a linear relationship between concentration and the instrument response has a coefficient of determination value $\left(\mathrm{R}^{2}\right)$ that is close to one for each drug.

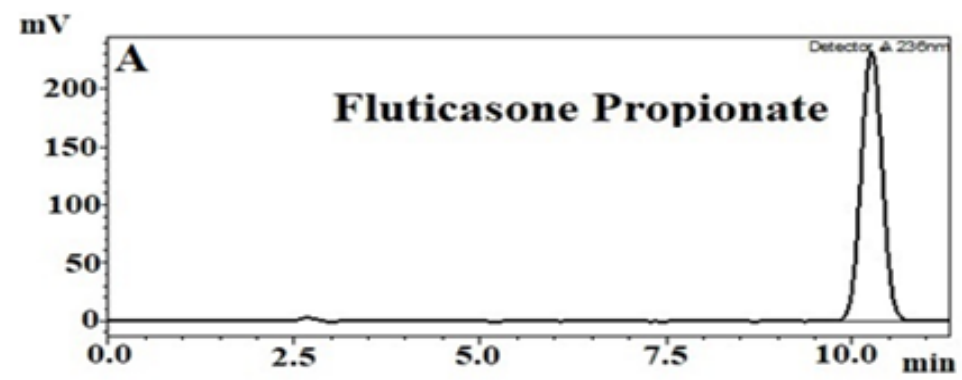

(a)

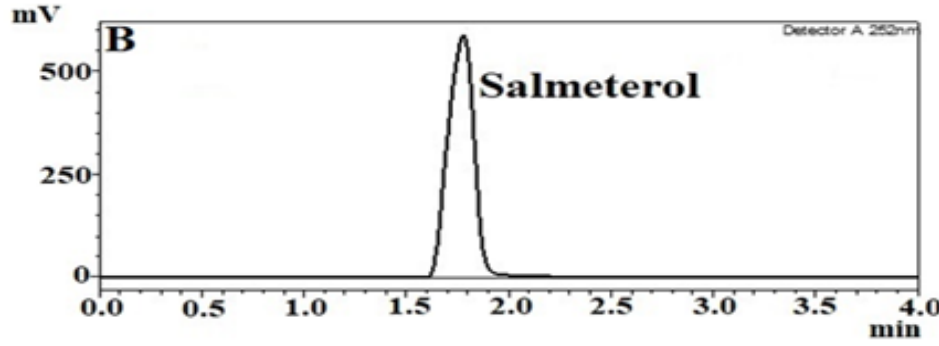

(b)

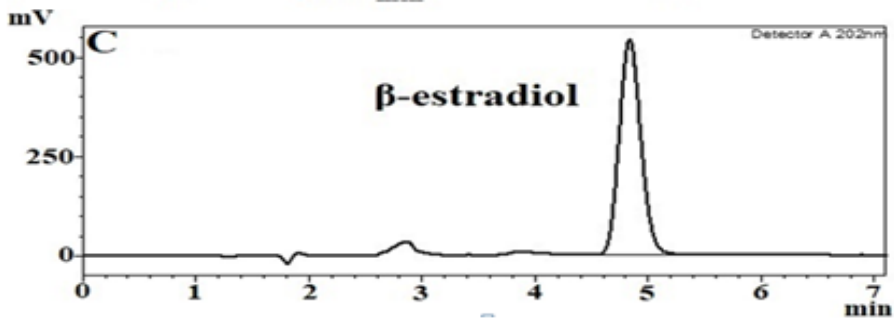

(c)

Fig. 2: Chromatograms of standard drugs using UV detection (a) FP, $236 \mathrm{~nm}$ (b) SX, $252 \mathrm{~nm}$ (c) $\beta E, 202 \mathrm{~nm}$

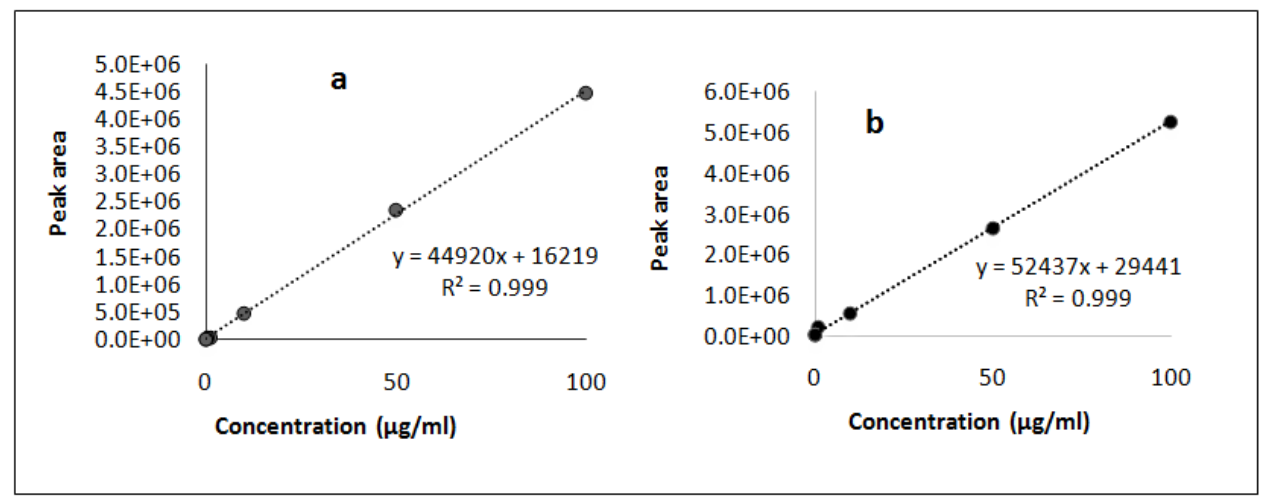

Fig. 3: Calibration curve for the concentration with the peak area of FP (a) and SX (b)

When (FP and SX) were combined with $\beta E$ as IS, the detection wavelength was programmed according to the timeprofile shown in (table 1). The retention times of detected peaks when the HYPERSIL column was used were $(10.6,1.8$, and $6 \mathrm{~min})$ for $\mathrm{FP}, \mathrm{SX}$, and $\beta \mathrm{E}$, respectively, and $(6.3,1.9$ and $4.7 \mathrm{~min})$ respectively, when the
SUPELCO column was used (fig. 4). The results show that the retention of the three medications using the SUPELCO column needs less time than that when using the HYPRSIL column. This may be due to the packing procedure of the stationary phase in the two columns. The SUPELCO column packing is more uniform than the HYPRSIL column. 
Table 1: HPLC programming of wavelength with time for the method, using HYPRSIL and SUPELCO columns

\begin{tabular}{llll}
\hline Column & Hyprsil & Supelco & Wavelength (nm) \\
\hline Time (min) & $0-4$ & $0-4$ & 252 \\
& $4-8$ & $4-5.30$ & 202 \\
& $8-11$ & $5.30-7$ & 236 \\
\hline
\end{tabular}

Although the retention time of tested drugs is varied according to the type of the mobile phase, column type, and size, column temperature, and flow rate. This method achieved good retention times for FP and SX using the C18 SUPELCO, which was not used in the previous studies for separation of FP and/or SX.

For example, in a previous study, an X-terra column $(250 \mathrm{~mm} \times 4.6$ $\mathrm{mm}, 5 \mu \mathrm{m}$ ) was used to elute FP and SX with mobile phase consisted of Methanol: Acetonitrile: Water (50:35:15 \% v/v) at $1 \mathrm{ml} / \mathrm{min}$ flow rate [12]. In other reported methods Acetonitrile: Methanol, Methanol: Water, buffered or modified mobile phases with different types of columns were used [9,11,26, 28-32].

\section{Linearity of calibration curves}

Nine Points calibration curves for each medication were constructed separately at concentration levels of $(0.067-100 \mu \mathrm{g} / \mathrm{ml})$ and $(0.0333-50 \mu \mathrm{g} / \mathrm{ml})$ for FP and SX respectively $(\mathrm{n}=7)$ as shown in (fig. 5). Calibration curves were linear over the specified range with accepted values of precision and accuracy (for concentrations $>3.33$ $\mu \mathrm{g} / \mathrm{ml}$ ), $\mathrm{R}^{2}$ values (statistically significant approved by One-way ANOVA test) for FP and SX are larger than 0.9984.

\section{Limit of detection (LOD) and limit of quantification (LOQ)}

The lowest detected concentrations with suitable accuracy and precision (LOQ) are 0.6 and $0.3 \mu \mathrm{g} / \mathrm{ml}$ for FP and SX, respectively. The lowest detected concentrations without getting precise and accurate replications (LOD) were 0.13 and $0.06 \mu \mathrm{g} / \mathrm{ml}$ for FP and SX, respectively.

Compared with similar previous studies (HPLC with UV detection methods), this study obtained a wider linearity range and lower LOD and LOQ levels. Sa Couto AR. et al. reported that LOD/IOQ for FP were $6.7 / 20.3 \mu \mathrm{g} / \mathrm{ml}$ at a linear range between 30 to $90 \mu \mathrm{g} / \mathrm{ml}$ [26]. Duran A. and Dogan HN. have tested FP and SX at linear ranges of 2$16 \mu \mathrm{g} / \mathrm{ml}$ and $1-8 \mu \mathrm{g} / \mathrm{ml}$, respectively [28]. Also, Pączkowska E. et al. found that the method is linear over a range of $0.04-32.5 \mu \mathrm{g} / \mathrm{ml}$ and $0.025-4.8 \mu \mathrm{g} / \mathrm{ml}$ for FP and SX, respectively [13]. While Shahanaz M. et al. have reported that the linear response of their method was ranged $40-200 \mu \mathrm{g} / \mathrm{ml}$ For FP and 5-25 $\mu \mathrm{g} / \mathrm{ml}$ for SX [12].

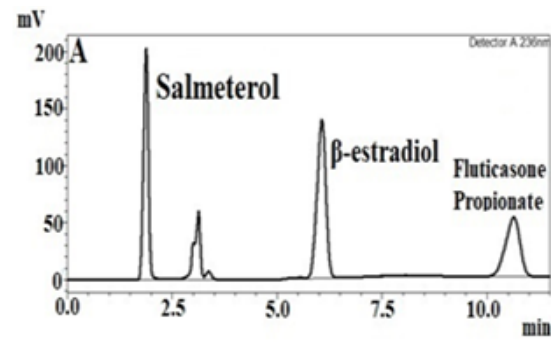

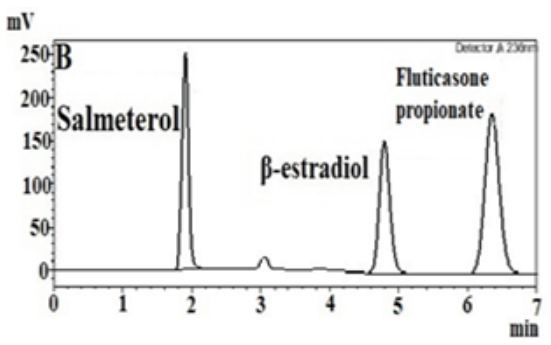

b

Fig. 4: HPLC chromatograms of the three medications when combined with changing wavelengths during the run time using (a) HYPRSIL column (b) SUPELCO column

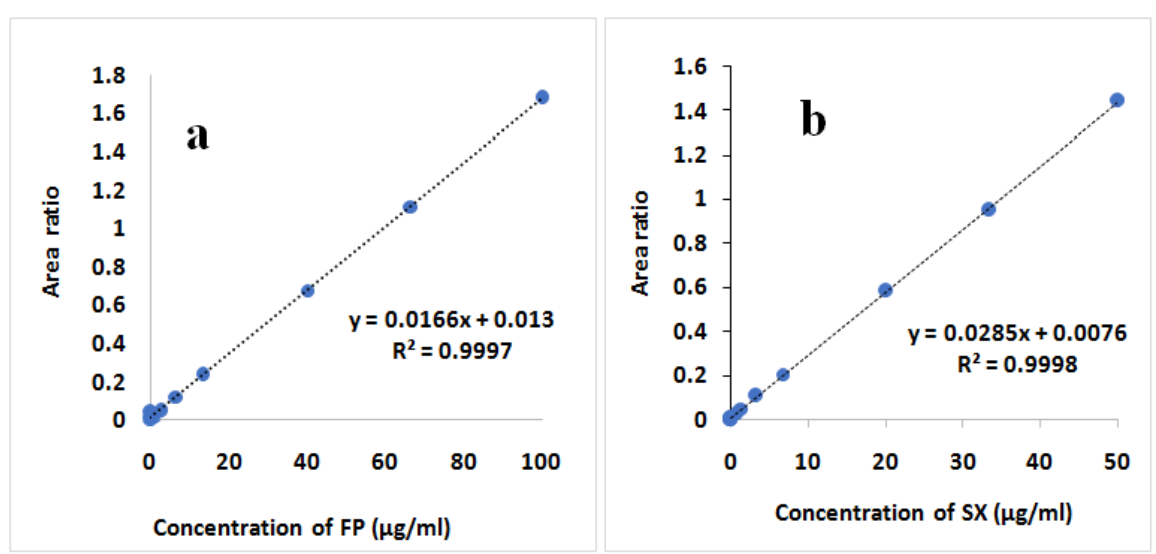

Fig. 5: Two representative curves of 7 for the calibration curves of (a) FP and (b) SX with a peak area ratio

\section{System/method precision and accuracy}

System and method precision of developed method were evaluated by relative standard deviation (RSD) at 4 concentration levels $(80$, 53.33, 0.67 and $0.2 \mu \mathrm{g} / \mathrm{ml}, \mathrm{n}=6)$ and $(40,26.67,0.33$ and $0.1 \mu \mathrm{g} / \mathrm{ml}$, $\mathrm{n}=6$ ) for FP and SX, respectively. The HPLC instrument used to develop the method and the method itself is precise since the relative standard deviations (RSD) values did not exceed 1.938, which means that the system and method precision results are within the acceptable range.

The accuracy of the developed methods for FP and SX was tested at the same concentration levels tested for precision. The highest interday relative error (RE) values at all concentration levels for either 
FP or SX were $2.714 \%$ and $0.641 \%$ for FP and SX, respectively, and did not exceed the acceptance value. The calibration curve standards with ranges of $(0.067-100.00 \mu \mathrm{g} / \mathrm{ml})$ and $(0.0333-50.000 \mu \mathrm{g} / \mathrm{ml})$ for FP and SX, respectively were constructed to recalculate the true values.

\section{Long-term thermal stability at room temperature and $0^{\circ} \mathrm{C}$}

Based on the results obtained of a long-term test at room temperature, the three large concentrations (53.33 and $80.00 \mu \mathrm{g} / \mathrm{ml}$ for FP and 26.67 and $40.00 \mu \mathrm{g} / \mathrm{ml}$ for SX) were found to be stable for the first $8 \mathrm{~d}$. This is attributed to the back-calculation results found within $\pm 5 \%$ of the theoretical concentration, and the relative recovery results found to be between 90 to $100 \%$ for the two medications. Relatively, the two medications start to decompose after $8 \mathrm{~d}$. The small concentrations of the two medications ( 0.67 and $0.33 \mu \mathrm{g} / \mathrm{ml}$ for FP and SX, respectively) are unstable and start to decompose gradually after $3 \mathrm{~d}$. On the other hand, the two medications are stable in methanolic solution at $0^{\circ} \mathrm{C}$ temperature for the time of the study ( $15 \mathrm{~d}$ ).

\section{Acidic, basic, and oxidative conditions stability}

Stress degradation to test the stability of the two medications in an acidic solution was employed. The results of the acidic conditions (1 $\mathrm{M} \mathrm{HCl}$ ) stability test of the two medications show that the recovery is less than $57 \%$ even for the highest concentration, Therefore, it is considered to be unstable under acidic conditions. Under basic conditions $(1 \mathrm{M} \mathrm{NaOH}), \quad F P$ solutions are unstable at all concentration levels (relative recovery was found to be less than 41 $\%)$, but for SX, only the large concentrations $(26.67$ and $40 \mu \mathrm{g} / \mathrm{ml})$ are stable (relative recovery was $100 \%$ and $113 \%$ )

Both FP and SX solutions are unstable under oxidation conditions since the relative recovery results are highly deviate from the initial concentration (not exceed $70 \%$ ).
Optimization and validation of a chromatographic method for simultaneous analysis of FP and SX in human plasma using HPLC with UV detector.

\section{Method optimization}

A highly sensitive and rapid method has been developed for the simultaneous determination of FP and SX from human plasma. The two medications can be quantitatively extracted by the liquid/liquid extraction method and analyzed using HPLC with a UV-Vis detector developed and validated as discussed above.

When testing the plasma baseline, no peaks were observed at the same retention times of FP or SX. A significant peak appeared at the same retention time of IS ( $\beta E$ ). Consequently, the method was then applied without using an internal standard. The method was applied by using a SUPELCO column. The blank chromatogram is shown in (fig. 6a).

The two medications of a concentration of $66.67 \mu \mathrm{g} / \mathrm{ml}$ were extracted from spiked human plasma and injected into the HPLC with a UV-Vis detector. Retention times of ( 6.3 and $1.9 \mathrm{~min}$ ) were detected for FP and SX, respectively as shown in (fig. 6b).

Recovery values extrapolated from the linear curve were ranged 94.98-102.46\% and $96.54-102.62 \%$ for FP and SX respectively indicate high efficiency of the extraction method of FP and SX from spiked plasma samples.

\section{Linearity and calibration curve}

Three calibration curves with the following concentrations points (6.67-66.67 $\mu \mathrm{g} / \mathrm{ml})$ and (3.33-33.3 $\mu \mathrm{g} / \mathrm{ml})$ for FP and SX, respectively, were extracted from spiked plasma and injected into the HPLC three times. The calibration graphs for FP and SX are in (fig. 7).

The developed method was linear within its specified range with accepted values of accuracy and precession since the $R^{2}$ of the analytes was $>0.9969$.
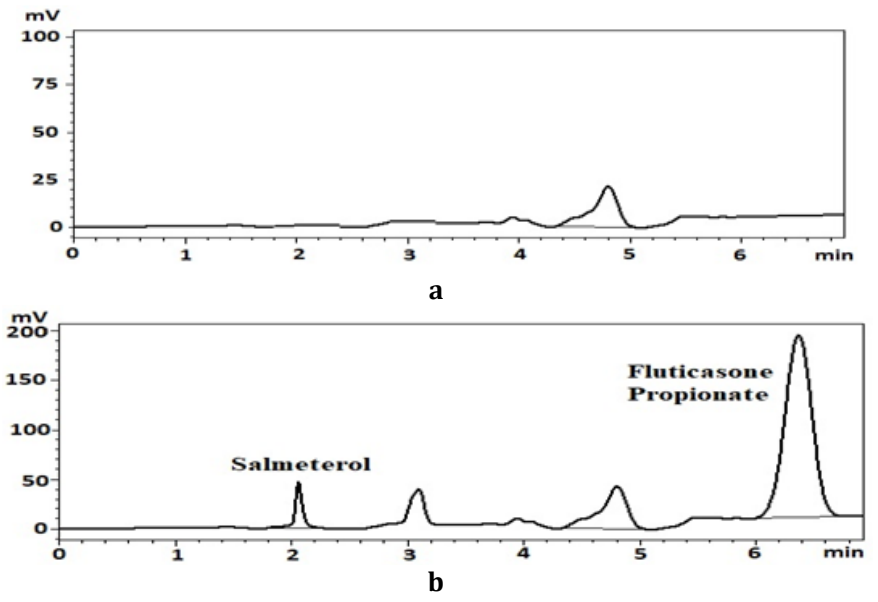

Fig. 6: HPLC chromatograms with changing wavelengths during the run time using a SUPELCO column for (a) Plasma blank. (b) The two medications were extracted from spiked plasma in combination
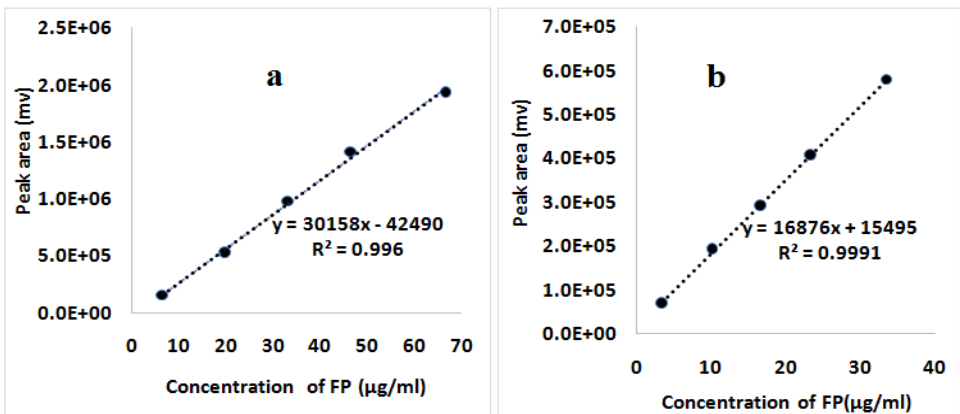

Fig. 7: Representative curves out of 3 for the calibration curves for the concentration of FP (a) and SX (b) extracted from plasma with peak area 


\section{Method accuracy}

The accuracy of developed methods, of FP and SX were tested at the concentration levels of $(53.33,40,26.67$ and $13.33 \mu \mathrm{g} / \mathrm{ml}, \mathrm{n}=3)$ and (26.67, 20.00, 13.33 and $6.67 \mu \mathrm{g} / \mathrm{ml}, \mathrm{n}=3$ ). The highest relative error (RE) value, at all concentration levels for either FP or SX, was found to be not more than $0.043 \%$.

To our knowledge, there is no HPLC-UV method for determining FP and SX in human plasma simultaneously. In the literature, only HPLC/Mass spectrometric methods were reported for analyzing FP and/or SX in human plasma using liquid-liquid or solid-liquid extraction techniques. Luigi Silvestro et al. analyzed FP and SX in plasma using LC/Tandem MS, Liquid-liquid extraction of spiked samples of FP and SX separately was done using diethyl ether then mixed and centrifuged at $4000 \mathrm{rpm}$ and reconstituted by acetonitrile: water, while the supported liquid extraction (SLE) method was done to isolate both FP and SX from human plasma [27].

Also, Krishnaswami S, et al. extracted FP from spiked plasma samples by $30 \%$ ethanol followed by solid-liquid extraction then reconstituted by methanol-water mixture. Samples were analyzed using LC-MS/MS [32]. A UPLC-MS/MS method was reported for detection of FP and its metabolites solid-phase extracted from human plasma [17].

\section{CONCLUSION}

A new, simple, rapid, accurate, and highly sensitive method was developed for the simultaneous determination of Fluticasone Propionate (FP) and Salmeterol Xinafoate (SX) in methanolic solution and human plasma using the HPLC instrument. The methods are valid for HPLC with UV detection. The simple nonbuffered mobile phase, short retention times, and low detection limits are the advantages of this work over the other studies in the literature for the same drugs.

\section{FUNDING}

Nil

\section{AUTHORS CONTRIBUTIONS}

All of the authors have contributed equally.

\section{CONFLICT OF INTERESTS}

The authors declare that they have no conflicts of interest.

\section{REFERENCES}

1. Shammout MJ, Bașci NE. Validated ultra-performance liquid chromatography-tandem mass spectrometric method for determination of betamethasone or dexamethasone in pharmaceuticals. Curr Pharm Anal 2018;14:68-75.

2. Pelt AC. Glucocorticoids: effects, action mechanisms, and therapeutic uses. Hauppauge, N. Y.: Nova Science; 2011.

3. Ashkin DP, Fabbri LM. Long-acting beta-agonists in the management of chronic obstructive pulmonary disease: current and future agents. Respi Res 2010;11:149.

4. Weersink EJ, Douma RR, Postma DS, Koeter GH. Fluticasone propionate, salmeterol xinafoate, and their combination in the treatment of nocturnal asthma. Am J Respir Crit Care Med 1997;155:1241-6.

5. Altaf M, Masood Q, Ahmed T, Ilyaz M, Basha S. Health related quality of life assessment using St. George's respiratory questionnaire in chronic obstructive pulmonary patients on combined inhaled corticosteroids and bronchodilators. Int J Pharm Pharm Sci 2016;8:445-9.

6. Hammad MA, Omar MA, Awad M. Validation of sensitive spectrophotometric method for determination of salmeterol xinafoate and fenoterol hydrobromide via o-phenanthroline and iron complexation. J Appl Pharm Sci 2017;7:49-54.

7. Kondawar MS, Shah RR, Waghmare JJ, Malusare MK, Shah ND. UV spectrophotometric method for simultaneous estimation of salmeterol xinafoate and fluticasone propionate in bulk and dosage form. Int J Pharm Tech Res 2011;3:1801-6.

8. Lakshmi K, Kesareddy R, Babu S, Kota R, Karri R, Jafer Vali Shaik. Simultaneous estimation of fluticasone propionate, azelastine hydrochloride, phenylethyl alcohol, and benzalkonium chloride by RP-HPLC method in nasal spray preparations. Int J Res Pharm Sci 2010;1:473-80.

9. Samir A, Salem H, Abdelkawy M. Simultaneous determination of salmeterol xinafoate and fluticasone propionate in bulk powder and seretide diskus using high performance liquid chromatographic and spectrophotometric method. Pharm Anal Acta 2012;3:1-7.

10. Murnane D, Martin GP, Marriott C. Validation of a reversephase high performance liquid chromatographic method for concurrent assay of a weak base (salmeterol xinafoate) and a pharmacologically active steroid (fluticasone propionate). J Pharm Biomed Anal 2006;40:1149-54.

11. Jain S, Gorle AP, Patil SS, Chavan RS, Bari PR. Stability indicating RP-HPLC method for estimation of salmeterol xinafoate in bulk and pharmaceutical formulation. Int J Pharm Chem Anal 2015;2:28-33.

12. Shahanaz M, Vageesh NM, Nizamuddin ND, Hazra B. Development and validation of an RP-HPLC-PDA method for simultaneous determination of Fluticasone and Salmeterol in bulk and pharmaceutical dosage form. Int J Med Pharm Sci 2018;3:25-8.

13. Pączkowska E, Smukowska D, Tratkiewicz E, Białasiewicz $P$. HPLC method for simultaneous determination of salmeterol xinafoate and fluticasone propionate for the quality control of dry powder inhalation products. Acta Chromatogr 2015;27:30920.

14. Masher HJ, Zech K, Masher DG. Sensitive simultaneous determination of ciclesonide, ciclesonide-M1-metabolite and fluticasone propionate in human serum by HPLC-MS/MS with APPI. J Chromatogr B: Anal Techno Biomed Life Sci 2008;869:84-92.

15. Van Eenoo P, Deventer K, Delbeke FT. Quantitative detection of salmeterol after inhalation in equine urine by liquid chromatography/tandem mass spectrometry. Rapid Commun Mass Spectrom 2002;16:1755-9.

16. Mauro D, Ciardullo S, Civitareale C, Fiori M, Pastorelli AA, Stacchini $\mathrm{P}$, et al. Development and validation of a multiresidue method for determination of $18 \beta$-agonists in bovine urine by UPLC-MS/MS. Microchem J 2014;115:70-7.

17. Nair SG, Patel DP, Sanyal M, Singhal P, Shrivastav PS, Simultaneous analysis of glucocorticosteroids fluticasone propionate and its metabolite fluticasone propionate $17 \beta$ carboxylic acid in human plasma by UPLC-MS/MS at sub $\mathrm{pg} / \mathrm{ml}$ level. J Pharm Biomed Anal 2017;135:1-7.

18. Kulkarni PN, Jadhav CK, Dodake Supekar AM, Gill CH. The quality by design approach for simultaneous determination of fluticasone propionate and salmeterol xinafoate. Int J Appl Pharm 2020;12:70-6.

19. Kasaye L, Hymete A, Mohamed AM. HPTLC-densitometric method for simultaneous determination of salmeterol xinafoate and fluticasone propionate in dry powder inhalers. Saudi Pharm J 2010;18:153-9.

20. Rajashi B Pharate, Suneela S Dhaneshwar. Stability-indicating high-performance thin-layer chromatography method for simultaneous estimation of formoterol fumarate dihydrate and fluticasone propionate in bulk drug and pharmaceutical dosage form. Asian J Pharm Clin Res 2019;12:149-55.

21. Michael Y, Chowdhry B, Ashurst I, Snowden M, Davies Cutting C, Gray S. The Physico-chemical properties of salmeterol and fluticasone propionate in different solvent environments. Int J Pharm 2000;200:279-88.

22. Hauser B, Deschner T, Boesch C. Development of a liquid chromatography-Tandem mass spectrometry method for the determination of 23 endogenous steroids in small quantities of primate urine. J Chromatogr B 2008;862:100-12.

23. Food and Drug Administration; 2003. Guidance for Industry Q1A (R2): stability testing of new drug substances and products; 2003.

24. Gonzalez 0, Alonso RM. Chapter 6-validation of bioanalytical chromatographic methods for the quantification of drugs in biological fluids. $\mathrm{H}$ and B Anal 2020;7:115-34.

25. International Conference on Harmonization (ICH) Harmonized Tripartite Guidelines, Validation of Analytical Procedures, Text, 
and Methodology, Q2 (R1), Parent Guidelines on Methodology; 1994.

26. SS Couto AR, Cardoso DE, Cabral Marques HM. Validation of an HPLC analytical method for the quantitative/qualitative determination of fluticasone propionate in inhalation particles on several matrices. Sci Pharm 2014;82:787-97.

27. Silvestro L, Savu SR, Savu SN, Tudoroniu A, Tarcomnicu I. Development of a sensitive method for simultaneous determination of fluticasone propionate and salmeterol in plasma samples by liquid chromatography-tandem mass spectrometry. Biomed Chromatogr 2012;26:627-35.

28. Duran A, Dogan HN, Ulgen M. Simultaneous quantitative determinations of fluticasone propionate and salmeterol xinafoate in diskus inhalers. Drug Metab Lett 2014;8:31-5.
29. Damle M, Choudhari S. Development and validation of stability indicating HPLC method for estimation of salmeterol xinafoate. J Pharm Qual Assur 2019;10:1865-9.

30. Cayır A, Cilen H, Sakızcı D, Turkyılmaz A. Method development and validation of simultaneous determination of related substances for salmeterol xinafoate and fluticasone propionate in dry powder inhalers. Chromatography Today 2017;4:14-9.

31. Acar S, Sakızcı D, Yilmaz E. Method development and validation of simultaneous determination of assay of salmeterol xinafoate and fluticasone propionate in dry powder inhalers. Chromatography Today 2020;3:32-6.

32. Krishnaswami S, Mollmann H, Derendorf H, Hochhaus G. A sensitive LC-MS/MS method for the quantification of fluticasone propionate in human plasma. J Pharm Biomed Anal 2000;22:123-9. 